\title{
Certain Integral Means Inequalities Involving Fractional Calculus Operators of Analytic Functions
}

\author{
Ravinder Krishna RAINA \\ Department of Mathematics, College of Technology \& Engineering \\ M.P. University of Agri. \& Technology \\ Udaipur-313001, Rajasthan, India \\ e-mail: rainark_7@hotmail.com \\ Indu Bala BAPNA \\ Department of Mathematics, Govt. Postgraduate College \\ Bhilwara 311001, Rajasthan, India
}

Received: January 2003

Abstract. This paper investigates a class of sharp integral means inequalities involving fractional calculus operators of certain analytic functions with negative coefficients. Some consequences of the main result are also mentioned.

Key words: fractional calculus operator, analytic functions, integral means.

\section{Introduction and Definitions}

Denote by $A$ the class of functions $f(z)$ defined by

$$
f(z)=z-\sum_{k=2}^{\infty} a_{k} z^{k}, \quad a_{k} \geqslant 0
$$

which are analytic in the open unit disk $U=\{z:|z|<1\}$. Then, a function $f(z)$ in $A$ is said to be in the class $P(\delta, \alpha)$ if and only if it satisfies the inequality

$$
\operatorname{Re}\left[\frac{z f^{\prime}(z)+\delta z^{2} f^{\prime \prime}(z)}{\delta z f^{\prime}(z)+(1-\delta) f(z)}\right]>\alpha, \quad z \in U ; 0 \leqslant \delta \leqslant 1 ; 0 \leqslant \alpha<1 .
$$

We note that

$$
P(0, \alpha)=S^{*}(\alpha) \text { and } P(1, \alpha)=K(\alpha)
$$

where the classes $S^{*}(\alpha)$ and $K(\alpha)$ denote the usual classes of starlike functions and convex functions of order $\alpha$, respectively (see, for example, Srivastava and Owa (Eds.), 1992). The class $P(\delta, \alpha)$ was studied by Altintas (1991), and we note the following: 
A function $f(z)$ of the form (1.1) belongs to the class $P(\delta, \alpha)$ if and only if

$$
\sum_{k=2}^{\infty}(k-\alpha)[1+(k-1) \delta] a_{k} \leqslant 1-\alpha .
$$

The extreme points of $P(\delta, \alpha)$ are given by the functions

$$
f_{k}(z)=z-\frac{1-\alpha}{(k-\alpha)[1+(k-1) \delta]} z^{k}, \quad k \geqslant 2 .
$$

The coefficient bounds and extreme points of functions belonging to the subclasses of functions emerging from the class $P(\delta, \alpha)$ can easily be deduced from (1.3) and (1.4), respectively. A mention of these special cases is made while considering interesting consequences of our main result in the concluding section.

Let $g(z)$ and $h(z)$ be analytic functions such that $g(0)=h(0)$. Then $g(z)$ is said to be subordinate to $h(z)$ (written as $g(z) \prec h(z)$ ) if there exists an analytic functions $w(z)$ so that $w(0)=0,|w(z)|<1(z \in U)$, and $g(z)=h(w(z))$.

DEFinition 1. The fractional calculus operator $J_{o, z}^{\lambda, \mu, \eta}$ of a function $f(z)$ (involving the familiar Gaussian hypergeometric function ${ }_{2} F_{1}$ ) is defined by Raina and Srivastava (1996) (see also (Raina and Choi, 2002) and (Raina and Nahar, 1999)):

$$
\begin{aligned}
& J_{o, z}^{\lambda, \mu} f(z)= \\
& =\frac{\mathrm{d}}{\mathrm{d} z}\left\{\frac{z^{\lambda-\mu}}{\Gamma(1-\lambda)} \int_{0}^{z}(z-t)^{-\lambda}{ }_{2} F_{1}\left(\mu-\lambda, 1-\eta ; 1-\lambda, 1-\frac{t}{z}\right) f(t) \mathrm{d} t\right\} \\
& \quad 0 \leqslant \lambda<1 ; \mu, \eta \in \mathbb{R},
\end{aligned}
$$

where the function $f(z)$ is analytic in a simply-connected region of the $z$-plane containing the origin, with the order

$$
f(z)=\mathrm{o}\left(|z|^{\varepsilon}\right), \quad z \rightarrow 0
$$

for

$$
\varepsilon>\max \{0, \mu-\eta\}-1 \text {. }
$$

It being understood that $(z-t)^{-\lambda}$ denotes the principal value for $0 \leqslant \arg (z-t)<2 \pi$, and is well defined in the unit $\operatorname{disk} U$.

DEFINITION 2. Under the hypothesis of Definition 1, the fractional calculus operator of order $\lambda+m$ is defined by Raina and Choi (2003)

$$
\begin{gathered}
J_{0, z}^{\lambda+m, \mu+m, \eta+m} f(z)=\frac{\mathrm{d}^{m}}{\mathrm{~d} z^{m}}\left(J_{0, z}^{\lambda, \mu, \eta} f(z)\right), \\
0 \leqslant \lambda<1 ; m \in \mathbb{N}_{0}(=\mathbb{N} \cup\{0\}),
\end{gathered}
$$


where $J_{0, z}^{\lambda, \mu, \eta} f(z)$ is the Saigo type fractional calculus operator defined by (1.5) above.

The operator $J_{0, z}^{\lambda, \mu, \eta}$ yields the vastly used fractional derivative operator ${ }_{0} D_{z}^{\lambda}$ of fractional calculus. Indeed, we have

$$
J_{0, z}^{\lambda, \lambda, \eta} f(z)={ }_{0} D_{z}^{\lambda} f(z), \quad 0 \leqslant \lambda<1,
$$

and the fractional derivative operator of order $\lambda+m\left(0 \leqslant \lambda<1, m \in \mathbb{N}_{0}\right)$ given by

$$
{ }_{0} D_{z}^{\lambda+m} f(z)=J_{0, z}^{\lambda+m, \lambda+m, \eta+m} f(z)
$$

The object of this paper is to establish a result giving the integral means inequality involving the fractional calculus operator (1.8) of certain classes of functions (with negative coefficients) which are analytic in open unit disk. The usefulness of the present investigation is that the main result provides an interesting unification of various similar results (which are proved rather independently) in a recent paper of Kim and Choi (2000). In the concluding section we discuss some of these special cases as worthwhile consequences of our main result.

\section{Results Required}

The following result (which follows easily from (Raina and Srivastava, 1996, p. 15)) will be required to establish our main result.

Lemma 1. Let $0 \leqslant \lambda<1, m \in \mathbb{N}_{0}, k>\max \{0, \mu-\eta\}-1$, then

$$
J_{0, z}^{\lambda+m, \mu+m, \eta+m} z^{k}=\phi(k) z^{k-\mu}
$$

where

$$
\phi(k)=\frac{\Gamma(k+1) \Gamma(k-\mu+\eta+1)}{\Gamma(k-\mu-m+1) \Gamma(k-\lambda+\eta+1)} .
$$

Lemma 2 (Littlewood, 1925). If $f$ and $g$ are analytic in $U$ with $g \prec f$, then, for $\beta>0$ and $0<r<1$

$$
\int_{0}^{2 \pi}\left|g\left(r \mathrm{e}^{i \theta}\right)\right|^{\beta} \mathrm{d} \theta \leqslant \int_{0}^{2 \pi}\left|f\left(r \mathrm{e}^{i \theta}\right)\right|^{\beta} \mathrm{d} \theta .
$$




\section{Main Result}

Theorem. Let $\beta>0$, and $f(z)$ defined by (1.1) be such that $f(z) \in P(\delta, \alpha)$. Then, for $z=r \mathrm{e}^{i \theta}(0<r<1)$ :

$$
\begin{aligned}
& \int_{0}^{2 \pi}\left|J_{0, z}^{\lambda+m, \mu+m, \eta+m} f(z)\right|^{\beta} \mathrm{d} \theta \leqslant \int_{0}^{2 \pi}\left|J_{0, z}^{\lambda+m, \mu+m, \eta+m} f_{2}(z)\right|^{\beta} \mathrm{d} \theta, \\
& 0 \leqslant \lambda<1 ; \mu<2-m ; \max (\lambda, \mu)-2<\eta \leqslant \frac{\lambda(\mu+m-3)-3 m}{\mu+m} ; m \in \mathbb{N}_{0},
\end{aligned}
$$

where $f_{2}(z)$ is given by

$$
f_{2}(z)=z-\frac{1-\alpha}{(2-\alpha)(1+\delta)} z^{k}
$$

Proof. Let the function $f(z)$ be defined by (1.1), then on using (2.1), we have

$$
\begin{aligned}
J_{0, z}^{\lambda+m, \mu+m, \eta+m} f(z) & =J_{0, z}^{\lambda+m, \mu+m, \eta+m} z-\sum_{k=2}^{\infty} a_{k}\left\{J_{0, z}^{\lambda+m, \mu+m, \eta+m} z^{k}\right\} \\
& =\phi(1) z^{1-\mu-m}\left(1-\sum_{k=2}^{\infty} a_{k} \frac{\phi(k)}{\phi(1)} z^{k-1}\right)
\end{aligned}
$$

where $\phi(k)$ is given by (2.2).

We observe that for $0 \leqslant \lambda<1, \mu<2-m\left(m \in \mathbb{N}_{0}\right), \eta>\max \{\lambda, \mu\}-2$, the inequality $\phi(k) \geqslant \phi(k+1), \forall k \geqslant 2$ is satisfied when $\eta \leqslant \frac{\lambda(\mu+m-3)-3 m}{\mu+m}$. Thus, under the constraints stated with (3.1), $\phi(k)$ is a decreasing function of $k$, and we have

$$
0<\phi(k) \leqslant \phi(2)=\frac{\Gamma(3) \Gamma(3-\mu+\eta)}{\Gamma(3-\mu-m) \Gamma(3-\lambda+\eta)} .
$$

Form (1.4), we have

$$
f_{2}(z)=z-\frac{1-\alpha}{(2-\alpha)(1+\delta)} z^{2}
$$

which yields

$$
J_{0, z}^{\lambda+m, \mu+m, \eta+m} f_{2}(z)=\phi(1) z^{1-\mu-m}\left(1-\frac{1-\alpha}{(2-\alpha)(1+\delta)} \frac{\phi(2)}{\phi(1)} z\right) .
$$

For establishing the inequality (3.1), we need to show that

$$
\int_{0}^{2 \pi}\left|1-\sum_{k=2}^{\infty} a_{k} \frac{\phi(k)}{\phi(1)} z^{k-1}\right|^{\beta} \mathrm{d} \theta \leqslant \int_{0}^{2 \pi}\left|1-\frac{1-\alpha}{(2-\alpha)(1+\delta)} \frac{\phi(2)}{\phi(1)} z\right|^{\beta} \mathrm{d} \theta .
$$


Making use of Lemma 2, it is sufficient to show that

$$
1-\sum_{k=2}^{\infty} a_{k} \frac{\phi(k)}{\phi(1)} z^{k-1} \prec 1-\frac{1-\alpha}{(2-\alpha)(1+\delta)} \frac{\phi(2)}{\phi(1)} z .
$$

Let us put

$$
1-\sum_{k=2}^{\infty} a_{k} \frac{\phi(k)}{\phi(1)} z^{k-1}=1-\frac{1-\alpha}{(2-\alpha)(1+\delta)} \frac{\phi(2)}{\phi(1)} w(z)
$$

Then, (3.4) on using (3.3) and (1.3) yields

$$
|w(z)|=\frac{(2-\alpha)(1+\delta)}{1-\alpha}\left|\sum_{k=2}^{\infty} \frac{\phi(k)}{\phi(2)} a_{k} z^{k-1}\right| \leqslant \frac{(2-\alpha)(1+\delta)}{1-\alpha}|z| \sum_{k=2}^{\infty} a_{k} \leqslant|z| .
$$

This completes the proof.

\section{Some Consequences of the Main Result}

In this section we discuss some interesting consequences of the main result. To this end, let us set $\alpha=\delta=0, \lambda=\mu$, in our Theorem, and choose $m=0,1$ and 2, then in view of (1.3), (1.4) and (1.9), we obtain the following inequalities which are contained in

Corollary 1. Let $\beta>0$, and $f(z)$ defined by (1.1) be such that $f \in T(=P(0,0))$. Then, for $z=r \mathrm{e}^{i \theta}(0<r<1)$ :

(i)

$$
\int_{0}^{2 \pi}\left|D_{z}^{\lambda} f(z)\right|^{\beta} \mathrm{d} \theta \leqslant \int_{0}^{2 \pi}\left|D_{z}^{\lambda} L_{2}(z)\right|^{\beta} \mathrm{d} \theta, \quad 0 \leqslant \lambda<1
$$

(ii)

$$
\int_{0}^{2 \pi}\left|D_{z}^{1+\lambda} f(z)\right|^{\beta} \mathrm{d} \theta \leqslant \int_{0}^{2 \pi}\left|D_{z}^{1+\lambda} L_{2}(z)\right|^{\beta} \mathrm{d} \theta, \quad 0 \leqslant \lambda<1
$$

(iii)

$$
\int_{0}^{2 \pi}\left|D_{z}^{2+\lambda} f(z)\right|^{\beta} \mathrm{d} \theta \leqslant \int_{0}^{2 \pi}\left|D_{z}^{2+\lambda} L_{2}(z)\right|^{\beta} \mathrm{d} \theta, \quad 0<\lambda<1,
$$

where $L_{2}(z)$ is given by

$$
L_{2}(z)=z-\frac{z^{2}}{2}
$$

Next, we put $\lambda=\mu, \alpha=0, \delta=1, m=1$ in the Theorem, then in view of (1.3), (1.4) and (1.9), we arrive at the following: 
Corollary 2. Let $\beta>0$, and $f(z)$ defined by (1.1) be such that $f \in C(=P(1,0))$. Then, for $z=r \mathrm{e}^{i \theta}(0<r<1)$ :

$$
\int_{0}^{2 \pi}\left|D_{z}^{1+\lambda} f(z)\right|^{\beta} \mathrm{d} \theta \leqslant \int_{0}^{2 \pi}\left|D_{z}^{1+\lambda} g_{2}(z)\right|^{\beta} \mathrm{d} \theta, \quad 0 \leqslant \lambda \leqslant 2 / 3
$$

where $g_{2}(z)$ is given by

$$
g_{2}(z)=z-\frac{z^{2}}{2^{2}}
$$

Again we put $\lambda=\mu, \delta=0$ and $m=0,1$, and 2 in the Theorem, then in view of (1.3) (1.4) and (1.9), we obtain the following:

Corollary 3. Let $\beta>0$, and $f(z)$ defined by (1.1) be such that $f \in T^{*}(=P(0, \alpha))$. Then, for $z=r \mathrm{e}^{i \theta}(0<r<1)$ :

$\begin{array}{ll}\text { (i) } \quad & \int_{0}^{2 \pi}\left|D_{z}^{\lambda} f\left(r \mathrm{e}^{i \theta}\right)\right|^{\beta} \mathrm{d} \theta \leqslant \int_{0}^{2 \pi}\left|D_{z}^{\lambda} h_{2}\left(r \mathrm{e}^{i \theta}\right)\right|^{\beta} \mathrm{d} \theta, \quad 0 \leqslant \lambda<1, \\ \text { (ii) } & \int_{0}^{2 \pi}\left|D_{z}^{1+\lambda} f\left(r \mathrm{e}^{i \theta}\right)\right|^{\beta} \mathrm{d} \theta \leqslant \int_{0}^{2 \pi}\left|D_{z}^{1+\lambda} h_{2}\left(r \mathrm{e}^{i \theta}\right)\right|^{\beta} \mathrm{d} \theta, \quad 0 \leqslant \lambda<1, \\ \text { (iii) } \quad & \int_{0}^{2 \pi}\left|D_{z}^{2+\lambda} f\left(r \mathrm{e}^{i \theta}\right)\right|^{\beta} \mathrm{d} \theta \leqslant \int_{0}^{2 \pi}\left|D_{z}^{2+\lambda} h_{2}\left(r \mathrm{e}^{i \theta}\right)\right|^{\beta} \mathrm{d} \theta, \quad 0<\lambda<1,\end{array}$

where $h_{2}(z)$ is given by

$$
h_{2}(z)=z-\frac{1-\alpha}{2-\alpha} z^{2}
$$

Lastly, we put $\lambda=\mu, \delta=1$ and $m=0,1$, and 2 and in the Theorem, then in view of (1.3), (1.4) and (1.9), we obtain the following results:

COROllary 4. Let $\beta>0$, and $f(z)$ defined by (1.1) be such that $f \in C^{*}(=P(1, \alpha))$. Then, for $z=r \mathrm{e}^{i \theta}(0<r<1)$ :

$\begin{aligned} \text { (i) } & \int_{0}^{2 \pi}\left|D_{z}^{\lambda} f\left(r \mathrm{e}^{i \theta}\right)\right|^{\beta} \mathrm{d} \theta \leqslant \int_{0}^{2 \pi}\left|D_{z}^{\lambda} \psi_{2}\left(r \mathrm{e}^{i \theta}\right)\right|^{\beta} \mathrm{d} \theta, \quad 0 \leqslant \lambda<1, \\ \text { (ii) } & \int_{0}^{2 \pi}\left|D_{z}^{1+\lambda} f\left(r \mathrm{e}^{i \theta}\right)\right|^{\beta} \mathrm{d} \theta \leqslant \int_{0}^{2 \pi}\left|D_{z}^{1+\lambda} \psi_{2}\left(r \mathrm{e}^{i \theta}\right)\right|^{\beta} \mathrm{d} \theta, \quad 0 \leqslant \lambda \leqslant 2 / 3,\end{aligned}$ 


$$
\int_{0}^{2 \pi}\left|D_{z}^{2+\lambda} f\left(r \mathrm{e}^{i \theta}\right)\right|^{\beta} \mathrm{d} \theta \leqslant \int_{0}^{2 \pi}\left|D_{z}^{2+\lambda} \psi_{2}\left(r \mathrm{e}^{i \theta}\right)\right|^{\beta} \mathrm{d} \theta, \quad 0<\lambda<1
$$

where $\psi_{2}(z)$ is given by

$$
\psi_{2}(z)=z-\frac{1-\alpha}{2(2-\alpha)} z^{2}
$$

From the above discussion of various consequences of our main result, we conclude this paper by remarking that the aforementioned results (Corollaries 1-4) which have been established earlier by Kim and Choi (2000), as separate independent theorems (see Theorems 1-3 in (Kim and Choi, 2000)), are, in fact, easily deducible from our main result. The involvement of the fractional calculus operator in the main result thus provides interesting unification of the results of Kim and Choi (2000) (which include the results of Silverman (1997)). The integral means inequalities which stem from the main result by assigning appropriate values to the various parameters can find applications in problems of computer engineering. Decompositional structures for optimal control in certain biomedical models can be developed utilising programming techniques with the imposition of constraints in the form of the above (or their reduced form) inequalities.

\section{Acknowledgements}

The work of the first-named author was supported by Council of Scientific \& Industrial Research (Govt. of India), New Delhi.

\section{References}

Altintas, O. (1991). On a subclass of certain starlike functions with negative coefficients. Math. Japon, 36, 489-495.

Kim, Y.C., and J.H. Choi (2000). Integral means of the fractional derivative of univalent functions with negative coefficients. Math. Japon, 51(3), 453-457.

Littlewood, J.E. (1925). On inequalities in the theory of functions. Proc. London Math. Soc., 23, 481-519.

Raina, R.K., and J.H. Choi (2002). On a subclass of analytic and multivalent functions associated with a certain fractional calculus operator. Indian J. Pure Appld. Math., 33(1), 55-62.

Raina, R.K., and J.H. Choi (2003). Some results connected with a subclass of analytic functions involving certain fractional calculus operators. J. Fracl. Cal., 13, 19-25 (to appear).

Raina, R.K., and T.S. Nahar (1999). On boundedness of fractional calculus operators involving certain classes of univalent functions. Hadronic J. Suppl., 14, 65-77.

Raina, R.K., and H.M. Srivastava (1996). A certain subclass of analytic functions associated with operators of fractional calculus. Comput. Math. Applic., 32, 13-19.

Silverman, H. (1997). Integral means for univalent functions with negative coefficients. Houston J. Math., 23 $169-174$.

Srivastava, H.M., and S. Owa (Eds.) (1992). Current Topics in Analytic Function Theory. World Scientific, Singapore. 
R.K. Raina is a professor of mathematics and also heads the department. His research interests are in the areas of special functions, integral transforms, fractional calculus, and the geometric function theory of complex analysis. He is member of several academic bodies, reviewer of various journals including the Math. Reviews and Zentralblatt für Mathematik.

I.B. Bapna is a lecturer in mathematics. She is pursuing her research under the supervision of prof. R.K. Raina.

Kai kurios integralu vidurkinės nelygybės, susijusios su operatoriu nuo analiziniu funkciju trupmeniniu skaičiavimu

Ravinder Krishna RAINA, Indu Bala BAPNA

Straipsnyje nagrinejjamos vidurkinès integralinès nelygybės, susietos su operatoriu, kuriu branduoliai yra hipergeometrinès funkcijos ir argumentai analizinès funkcijos, trupmeniniu skaičiavimu. Pateikiama keliolika konkrečių nelygybių, išplaukiančių iš pagrindinio rezultato. 